\title{
Mental disorders in Bangladesh: a systematic review
}

\author{
Mohammad Didar Hossain ${ }^{1}$, Helal Uddin Ahmed ${ }^{2}$, Waziul Alam Chowdhury ${ }^{2 \dagger}$, Louis Wilhelmus Niessen ${ }^{3,4 \dagger}$ \\ and Dewan Shamsul Alam ${ }^{1 *}$
}

\begin{abstract}
Background: Mental disorders constitute a major public health problem globally with higher burden in low and middle-income countries. In Bangladesh, systematically-collected data on mental disorders are scarce and this leaves the extent of the problem not so well defined. We reviewed the literature on mental health disorders in Bangladesh to summarize the available data and identify evidence gaps.

Methods: We identified relevant literature on mental disorders within Bangladesh published between 1975 and October, 2013 through a systematic and comprehensive search. Relevant information from the selected articles was extracted and presented in tables.

Results: We identified 32 articles which met our pre-defined eligibility criteria. The reported prevalence of mental disorders varied from 6.5 to $31.0 \%$ among adults and from 13.4 to $22.9 \%$ among children. Some awareness regarding mental health disorders exists at community level. There is a negative attitude towards treatment of those affected and treatment is not a priority in health care delivery. Mental health services are concentrated around tertiary care hospitals in big cities and absent in primary care.

Conclusions: The burden of mental disorders is high in Bangladesh, yet a largely unrecognized and under-researched area. To improve the mental health services in Bangladesh, further well-designed epidemiological and clinical research are needed.
\end{abstract}

Keywords: Mental disorders, Depression, Systematic review, Prevalence, Comorbidity, Service delivery, Management, Treatment, Bangladesh

\section{Background}

Mental disorders constitute a major public health problem and contribute to $13 \%$ of the global burden of disease measured as disability adjusted life years [1]. Low and middle income countries have higher burden of mental disorders than economically developed countries [2,3]. Mental disorders have serious negative effect on survival, and when present with chronic diseases as comorbid condition, serious mental disorders may reduce life expectancy by about 20 years [4]. Mental disorders are generally not perceived as a health problem and are not priority in the health care delivery. Epidemiological

\footnotetext{
* Correspondence: dsalam@icddrb.org

${ }^{\dagger}$ Equal contributors

${ }^{1}$ Centre for Control of Chronic Diseases (CCCD), International Centre for Diarrheal Disease Research, Bangladesh (icddr,b), 68 Shaheed Tajuddin Ahmed Sharani, Mohakhali, Dhaka 1212, Bangladesh

Full list of author information is available at the end of the article
}

and health system data related to mental disorders are scarce and are not readily available in Bangladesh although a few published articles provide some estimates of different mental disorders.

This review was conducted to understand the prevailing situation and trends in mental disorders in Bangladesh. This is expected to generate useful insights and may assist health professionals and policy makers in defining the need and planning service delivery models.

\section{Methods \\ Search strategy}

We searched, collected and evaluated literature on mental disorders based on the Preferred Reporting Items for Systematic Reviews and Meta-Analyses (PRISMA) checklist [5]. The PRISMA protocol was chosen from several methodologies and guidelines for the optimal reporting of 
systematic reviews specifically for quantitative studies. We followed the PRISMA checklist [5] for the extraction and tabulation of information. We identified relevant community and facility based literature through a comprehensive scientific literature search using the data-bases of PubMed and the Bangladesh Journals Online. We used the following search terms: "mental disorders, depression, prevalence, comorbidity, service delivery, referral, management, treatment, Bangladesh". We combined search terms using Boolean operators to narrow the search results. We carried out a manual search to identify additional articles was carried out based on the bibliographies of the identified published studies ('snowballing'). References and cross-references of the articles were critically studied through manually to find any relevant study missed by the electronic and/or manual search. Additionally, local journals that could not be accessed online were also searched manually. We also retrieved the full-text for the unpublished/gray literature from the library and Information Services Unit (LISU) of the icddr,b and library of the National Institute of Mental Health (NIMH) Bangladesh. Citations were managed using EndNote version X7.0.2. A narrative synthesis of the finally selected articles was reported.

\section{Inclusion and exclusion criteria}

We included articles which presented (i) quantitative outcome data on mental disorders among Bangladeshi population, (ii) reported on human participants and (iii) were published between 1975 (earliest listed publication in Bangladesh) and October, 2013 (latest publication obtained) and (iv) published in English. We excluded articles which were: (i) qualitative studies, (ii) those published as theses/ dissertations, and (iii) not in English.

\section{Quality assessment}

Initially, two authors (MDH \& DSA) screened and evaluated each article individually to decide on its inclusion or exclusion. Articles were further assessed for (i) the appropiateness and clarity of the research question/objectives/aims $(y / n)$ and the study design chosen $(y / n)$, (ii) adequate description of study location $(\mathrm{y} / \mathrm{n})$, sample/ participants $(y / n)$, data collection methods $(y / n)$, context of collection and quantitative outcome data presented $(y / n)$ (iii) adequacy of measurement and appropiateness of statistical analysis (e.g. the odds ratio, $p$ values and confidence interval) $(\mathrm{y} / \mathrm{n})$. For each article found, titles and abstracts were initially examined to determine whether the selection criteria were met. If an article failed to meet these criteria, the full text article was not retrieved and was excluded. In case of any disagreement on quality assessment checklist, three authors (MDH, HUA \& DSA) discussed together and reached an agreement about inclusion or exclusion of that particular article.
We categorized the articles and tabulated by (1) study location: "rural and urban" (2) study method: "prevalence/cross-sectional study, case control, cohort, specific population survey and trials", and by (3) outcome: "mental disorders, adult prevalence, child prevalence, service delivery/referral pattern/management/treatment, types of co-morbidity". A record of all excluded studies and the reasons for exclusion was documented. The selection process of the articles is displayed in Figure 1.

\section{Results}

\section{Selection of literature}

Through the initial search of databases, we identified 107 articles on mental disorders in Bangladesh. After the review of titles and the abstracts we excluded 54 articles as they were deemed not relevant to the review. Out of the remaining 53 articles, 3 failed to meet the screening criteria and full text of the remaining 50 articles were further reviewed and checked for eligibility which resulted in further exclusion of another 18 articles, 5 of which were due to qualitative in nature [6-10] and 13 did not fulfill the required methodological criteria. Finally, 32 studies met the inclusion criteria for the review (Figure 1). Most common mental disorders in the selected articles were major anxiety, depression and overall psychiatric disorders.

Altogether 13 articles reported prevalence, six reported service delivery, six on management and another seven on depression as comorbid condition. Only 5 of the 13 prevalence studies published in international journals provided adequate details of methods. Among the articles reported prevalence, 9 studies were community based studies. Diagnosis in all the 5 studies was either made by a psychiatrist or a trained worker using validated instruments, and was considered as good quality. Only 2 studies [11,12] discussed the generalizability of their findings along with the study limitations. We did not find any prospective study presenting the natural course of the disorder or any rigorously controlled study of any intervention.

\section{Prevalence of mental disorders among adults}

Table 1 presents summary of 8 cross-sectional studies that reported the prevalence of mental disorders in adult populations with sample sizes ranging from 327 to 13,080 participants.

Most commonly used screening and diagnostic tools in these studies were Self Reporting Questionnaire (SRQ), General Health Questionnaire (GHQ), and Structured Clinical Interview for Diagnostic and Statistical Manual of Mental Disorders (SCID). However, 3 articles published in local journals did not clarify type of tools used. The earliest preliminary study conducted in urban setting back in 1975 reported 31\% of out-patients had pure psychogenic conditions [13]. Later a general practice (GP) 


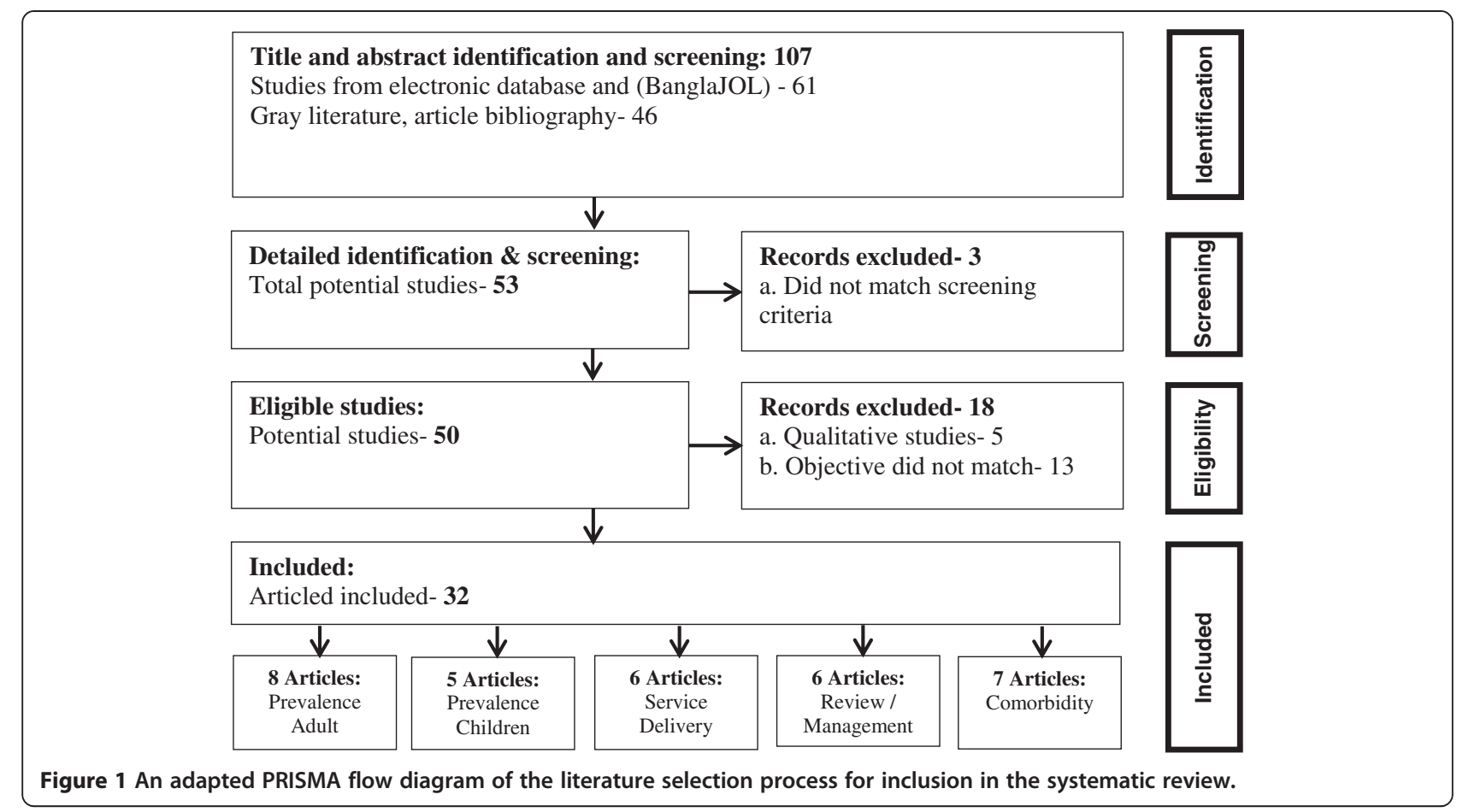

urban setting revealed $29 \%$ of the patients were suffering the same [14]. A community based rural study reported $3.6 \%$ psychiatric disorders and $2.9 \%$ both psychiatric and physical disorders with depression and anxiety being the most common condition [15]. Later an urban communitybased study reported psychiatric disorders among $28 \%$ of the participants as diagnosed by a psychiatrist [16]. Another study reported an overall prevalence of mental disorders among 12.2\% respondents but more females than males were affected (13.9\% vs. 10.2\%) [17]. A rural community-based study showed an overall prevalence of psychiatric disorders as 16.5\%; notably, half of the sufferers had depressive disorders (8\%) and a third had anxiety disorders (5\%) [18]. On the other hand, another study on females in a rural setting reported $16.4 \%$ had mental disorders with depression being the single most common disorder (8.9\%) [19]. The first national survey on mental health [12] conducted between 2003 and 2005 documented that $16.1 \%$ of the adult population had mental disorders and the prevalence was higher in women than men [12]. Overall, the literature evidence suggest the prevalence of mental disorders ranges from 6.5 to $31.0 \%$ among adults depending on the community or clinic setting, and women seemed to be more vulnerable.

\section{Prevalence of mental disorders among children}

Table 2 shows the summary of articles reporting prevalence of mental disorders in children. Sample sizes of the

Table 1 Summary of the studies reported prevalence of mental disorders in adult population

\begin{tabular}{|c|c|c|c|c|c|c|c|}
\hline $\begin{array}{l}\text { Author's and } \\
\text { publication year }\end{array}$ & $\begin{array}{l}\text { Year of data } \\
\text { collection }\end{array}$ & Setting & $\begin{array}{l}\text { Place of } \\
\text { the study }\end{array}$ & $\begin{array}{l}\text { Age range } \\
\text { (years), sexes }\end{array}$ & n (sample size) & $\begin{array}{l}\text { Outcome measures } \\
\text { instruments }\end{array}$ & Prevalence \\
\hline Chowdhury, 1975 [13] & 1974 & Urban & F (OPD, Hospital) & $\geq 13$ (both) & 652 & NA & $31.4 \%$ \\
\hline Alam, 1978 [14] & 1976-1977 & Urban & $F(G P)$ & All (both) & 1,764 & NA & $29 \%$ \\
\hline Chowdhury et al., 1981 [15] & 1978 & Rural & C & All (both) & 1,181 & NA & $6.5 \%$ \\
\hline Ara et al., 2001 [19] & 2000 & Rural & C & 18-65 (women) & 415 & GHQ-60 & $16.38 \%$ \\
\hline Islam et al., 2003 [16] & 1996-1997 & Urban & C & $\geq 18$ (both) & 1,145 & SRQ & $28 \%$ \\
\hline Karim et al., 2006 [17] & 2003 & Rural \& Urban & C & $\geq 18$ (both) & 327 & $S R Q, S C I D N P$ & $12.2 \%$ \\
\hline Hosain et al., 2007 [18] & 2000 & Rural & C & 18-60 (both) & 766 & GHQ-60 & $16.5 \%$ \\
\hline $\mathrm{NIMH}, \mathrm{B}$ and $\mathrm{WHO}, 2007$ [12] & 2003-2005 & Rural \& Urban & C & $\geq 18$ (both) & 13,080 & SRQ, SCID & $16.1 \%$ \\
\hline
\end{tabular}

$\mathrm{NA}=$ Not available, both = male and female, $\mathrm{C}=$ Community based study, F = Facility based study, OPD = Out Patient Department, GP = General Practice, GHQ $60=$ General Health Questionnaire 60, SRQ = Self-Reporting Questionnaire, SCID = Structured Clinical Interview for Diagnostic and Statistical Manual of Mental Disorders (DSM-IV), SCID NP = Structured Clinical Interview for diagnosis: non-patient version. 
Table 2 Summary of the studies reported prevalence of mental disorders in children

\begin{tabular}{|c|c|c|c|c|c|c|c|}
\hline $\begin{array}{l}\text { Author's and } \\
\text { publication year }\end{array}$ & $\begin{array}{l}\text { Year of data } \\
\text { collection }\end{array}$ & Setting & $\begin{array}{l}\text { Place of } \\
\text { the study }\end{array}$ & $\begin{array}{l}\text { Age range } \\
\text { (years), sexes }\end{array}$ & n (sample size) & $\begin{array}{l}\text { Outcome measures } \\
\text { instruments }\end{array}$ & Prevalence \\
\hline Rabbani et al., 1999 [20] & 1994 & Urban school & $\mathrm{S}$ & NA (both) & 1,288 & Rutter's B2 Scale & $13.4 \%$ \\
\hline Jahan, 2004 [21] & 1997-1998 & Urban slum & $S$ & 10-16 (both) & 210 & $\begin{array}{l}\text { Semi- structured } \\
\text { questionnaire }\end{array}$ & $22.9 \%$ \\
\hline Mullick, 2005 [23] & $2002-2004$ & $\begin{array}{l}\text { Rural, Urban } \\
\text { and Urban Slum }\end{array}$ & C & 5-10 (both) & 922 & SDQ DAWBA & $15.2 \%$ \\
\hline Khan et al., 2008 [24] & $2001-2003$ & Rural & C & 2-9 (both) & 453 & TQ & $14.6 \%$ \\
\hline Rabbani et al., 2009 [11] & 2009 & Rural \& Urban & C & 5-17 (both) & 3,564 & RQC & $18.4 \%$ \\
\hline
\end{tabular}

$\mathrm{NA}=$ Not available, both = male and female, $\mathrm{C}=$ Community based study, F = Facility based study, $\mathrm{S}=$ School based study, UCEP = Underprivileged Children's Education Programme, Rutter's B2 Scale = Rutter's Behaviour Scale (B2), SDQ = Strengths and Difficulties Questionnaire, DAWBA = Development and Well-Being Assessment, $\mathrm{TQ}=$ Ten Questions, $\mathrm{RQC}=$ Reporting Questionnaire for Children.

studies varied from 210 to 3,564. Earliest report among urban primary school children revealed $13.4 \%$ had some type of behavioral disorder, with boys being twice more affected than girls (20.4 vs. 9.9\%) [20]. However, a study among socially disadvantaged (urban slum) children, reported $22.9 \%$ had some form of psychiatric disorder with slightly lower prevalence in boys than girls $(20.0 \%$ in boys and 25.5\% in girls) [21]. Mullick \& Goodman used Development and Well- Being Assessment (DAWBA) questionnaire, and previously validated Strengths and Difficulties Questionnaire (SDQ) tools [22] in their study and found overall prevalence of $15.2 \%$ in different settings (rural, urban and urban slum) with the highest prevalence in the urban slum (19.5\%) [23]. Another study found $14.6 \%$ children with behavioral problems as reported by the parents in rural Bangladesh [24]. Another more recent community-based study reported prevalence of mental disorder among $18.4 \%$ of the children [11].

\section{Depression and comorbidity}

Depression is a common comorbid condition with chronic diseases [25]. Table 3 presents the summary of the seven articles reported depression as comorbidity. Five of the studies were hospital-based and the other two were community-based. Six of the studies used cross-sectional and one used case-control study design [26]. An urban hospital-based study reported that among $47 \%$ patients with stroke and $54 \%$ of cancer patients had depressive episode [27]. Another hospital-based study found 56.6\% of cancer patients with major depressive disorders [28]. An urban facility-based study on outpatients reported $16 \%$ with purely psychiatric illness and about $3 \%$ of the total or $18.2 \%$ of purely psychiatric disorders had major depressive disorders [29]. A case control study in rural population concluded that newly diagnosed diabetic patients were four times more likely to have depressive symptoms than those without diabetes and females were more vulnerable than males [26]. Another recent study found depressive symptoms among 34\% of diabetes outpatients [30]. One study which was a part of a larger longitudinal epidemiological study on diabetes in rural Bangladesh [31] found $15.3 \%$ of the participants with depression [32]. An urban facility-based study reported presence of depression in one in every three diabetes patients [33].

\section{Service delivery and management}

In total, twelve articles were found (data not shown) where six [34-39] reported on care seeking pattern, referral and service delivery issues and the other six [40-45] reviewed management of psychiatric disorders in Bangladesh. In a pathway study it was found that only $16 \%$ patients came directly to mental health professionals [34]. On the other hand, a significant proportion consulted other care providers including native or religious healers and traditional healers $[34,36,43]$. Reports indicate that most of the care seekers were referred by old patients, relatives or friends $[35,38,43]$. Some studies reported long delays in care seeking. A rural study found that two third (65.4\%) of the mental patients from rural setting were referred to the hospital 3 months to several years after onset of the disorder [39] whereas in the urban setting the mean delay was about 10 weeks [34]. The main reason for delay was lack of awareness of the seriousness of the condition (69\%) [35]. Several articles pointed out the lack of adequate number of psychiatrists given the huge burden of mental health disorders and those available are mostly located in big cities. Notably, mental health services are virtually non-existent at primary care level throughout the country $[40,41,44]$.

\section{Discussion}

We found only a limited number of published studies on the prevalence of psychiatric disorders in Bangladesh. Overall prevalence varied from 6.5 to $31 \%$ among adults and from 13.4 to $22.9 \%$ among children. Despite wide ranges in prevalence estimates reported, these figures strongly suggest that mental disorders constitute a big public health problem in Bangladesh. 
Table 3 Summary of the studies reported depression as co-morbid condition

\begin{tabular}{|c|c|c|c|c|c|c|c|}
\hline $\begin{array}{l}\text { Author's and } \\
\text { publication year }\end{array}$ & $\begin{array}{l}\text { Year of data } \\
\text { collection }\end{array}$ & Setting & $\begin{array}{l}\text { Place of } \\
\text { the study }\end{array}$ & n (sample size) & $\begin{array}{l}\text { Outcome measures } \\
\text { instruments }\end{array}$ & Disease (n) & Comorbidity (n) \\
\hline $\begin{array}{l}\text { Karim et al., } \\
2001[27]\end{array}$ & $1995-98$ & Urban & F (Hospital) & 128 & $\begin{array}{l}\text { ICD } 10 \text { criteria; } \\
\text { Multipoint questionnaire }\end{array}$ & $\begin{array}{l}\text { Stroke (32) } \\
\text { Cancer (50) }\end{array}$ & $\begin{array}{l}\text { Depression (15) } \\
\text { Depression (27) }\end{array}$ \\
\hline $\begin{array}{l}\text { Chowdhury et al., } \\
2007 \text { [28] }\end{array}$ & 2007 & Urban & F (Hospital) & 100 & $\begin{array}{l}\text { DSM-IV criteria; } \\
\text { Structured questionnaire }\end{array}$ & Cancer (100) & Depression (30) \\
\hline $\begin{array}{l}\text { Ali et al., } \\
2007 \text { [29] }\end{array}$ & $2004-2006$ & Urban & F (Hospital) & 415 & DSM-IV criteria GHQ-12 & Illness (415) & Depression (12) \\
\hline $\begin{array}{l}\text { Asghar et al., } \\
2007 \text { [26] }\end{array}$ & 2004 & Rural & C & 952 & MADRS & Diabetes (184) & Depression (55) \\
\hline $\begin{array}{l}\text { Roy et al., } \\
2012 \text { [30] }\end{array}$ & $2010-2011$ & $\begin{array}{l}\text { Urban and } \\
\text { suburban }\end{array}$ & $\mathrm{F}(\mathrm{OPD}$, clinic) & 417 & WHO-5 and PHQ- 9 & Diabetes (417) & Depression (142) \\
\hline $\begin{array}{l}\text { Bhowmik et al., } \\
2012 \text { [32] }\end{array}$ & 2009 & Semi urban & C & 2293 & MADRS & Diabetes (181) & Depression (57) \\
\hline $\begin{array}{l}\text { Rahman et al., } \\
2011 \text { [33] }\end{array}$ & 2009 & Urban & F (Hospital) & 178 & CES-D & Diabetes (178) & Depression (62) \\
\hline
\end{tabular}

2011 [33]

$\mathrm{C}=$ Community based study, F = Facility based study, ICD $10=$ International Statistical Classification of Diseases and Related Health Problems, DSM- IV = Diagnostic and Statistical Manual of Mental Disorder- $4^{\text {th }}$ edition, GHQ $12=$ General Health Questionnaire, MADRS = Montgomery and Aasberg Depression Rating Scale, WHO-5 = World Health Organization-5 Well Being Index, PHQ- $9=$ Patient Health Questionnaire-9, CES-D = Centre for Epidemiological Studies Depression Scale.

It is worthwhile to mention some of the limitations of the review. Data from the selected articles are not comparable due to differences in settings (clinic- vs. community-based), different assessment tools and the different thresholds used to determine the psychiatric disorders. Therefore the various prevalence estimates available could not be used properly to assess the trend over time. Our review may have been subject to publication and selection bias as we were unable to contact the experts and collect unpublished materials or access any grey literature.

In general, the prevalence estimates of psychiatric disorders are prone to underestimation as majority of patients and their families deny due to strong stigma attached to mental disorders. This limits the number of affected patients seeking health care actively [43].

The prevalence reported by Islam et al. [16] might have underestimated due to focusing on only the major types of psychiatric disorders. There is wide variation between rural communities and also between rural and urban settings $[15,18]$. The prevalence reported in an urban overcrowded community was much higher as the study included older people who are more prone to mental disorders [16]. This review suggests both rural [15] and urban [13] settings a higher vulnerability of mental disorders among females as compared to males. There is a significantly higher prevalence of mental disorders among economically poor respondents, and specifically among women from large families as reported by Hosain et al. [18]. These findings are consistent with another rural study [19] which reported that social stigma inhibits women from seeking medical treatment for their mental problems. Despite considerable variations in the design of studies, prevalence of psychiatric disorders in adult population is more or less similar to socio-culturally similar settings in neighboring India [46] and Pakistan [47].

The only national survey conducted between 2003 and 2005 illustrated the high burden of mental disorders in Bangladesh [12]. As there is no similar nationally representative mental health survey carried out in recent time, it is not possible to assess the change and to estimate overall need for resources to address the mental health burden. In general, tools for screening and cut-off values used in the reported studies contributed to the variation in the prevalence reported in different articles. However, the problems of underreporting and under-diagnosis of mental disorders are major challenges for the future of psychiatric epidemiology in Bangladesh.

As evident from this review, data on mental disorders among children in Bangladesh are quite scanty. Moreover, the comparison of prevalence studies of childhood psychiatric disorders is challenging due to the heterogeneous nature of samples, screening and diagnostic tools used, and methods of combining information in addition to differences in age distributions which requires standardization for fair comparison. The overall prevalence of psychiatric disorders in a community study by Mullick \& Goodman [23] did not differ much with the findings of study by Rabbani et al. [11]. As there are only a handful of child mental health professionals with specialized training in Bangladesh, the vast gap between actual need and available services requires special and immediate attention [23]. Research in socially disadvantaged and underprivileged groups is also needed to improve the diagnosis, treatment and outcomes in those vulnerable groups [21]. Childhood psychiatric disorders were significantly associated with malnutrition [24], rural residence, low 
education of fathers, and positive family history [11] which all need a multi-sectorial approach to address these neglected areas. The children mental health survey [11] results provided a baseline measure and resources which can be a basis for taking initiatives for further prevalence study as well as creating provision for effective service delivery models.

The interaction between mental disorder and chronic diseases is complex, yet risks and causalities are wellestablished [48]. Mental disorder may increase the risk for chronic disorders and many chronic disorders can increase an individual's risk for developing mental disorders, thereby complicating help-seeking, diagnosis, management and prognosis [49].

Current epidemiological evidence suggested at least one third of people with diabetes are suffering from depressive disorders [50,51]. Although in this review we found four articles $[26,30,32,33]$ which reported similarly high prevalence of depression among diabetics. It is reported that more than half of the cancer patients suffer from depression $[27,28]$ which is conceivable given the severity and progressive nature of the disease, high cost and lack of adequate care facilities available. Limited data from South Asian settings reported two- to fivefold increase in the prevalence rates of depression in people with diabetes compared to people without diabetes [52-54]. Depressions intensify symptom presentation and interfere with the physical treatment [27]. Psychiatric morbidity is considerable among the cancer patients that need to be addressed with additional treatment and support [28]. These findings suggest a need for further rigorous study of chronic diseases and mental health for optimizing treatment of both conditions using sound methodologies as well as validated screening and diagnostic tools.

This review confirms inadequate care seeking as well as poor service delivery for mental health disorders. Referrals of patient with mental disorders to mental health specialists by the general practitioners or other health care providers are almost non-existent. The referral is also hampered due to superstitious beliefs related to psychiatric disorders. These are seen as triggered by evil influences while this leads to seeking remedies from traditional healers. These potentially harmful practices can be minimized through mass awareness [34,39] and development and implementation of mental health guidelines. This also can be influenced through raising individual level awareness and social mobilization [55]. Denial mental health problems is common among the general population as they perceive these conditions as untreatable. Additional constraint is imposed by lack adequately trained general practitioners and health workers at primary care level. There are no structured and organized mental health services available at primary and even at secondary health care level.
Although women are more often sufferers and also more vulnerable to develop psychiatric disorders, they are more neglected than males in receiving care. This is more likely the result of a male-dominated culture in Bangladesh [38]. Therefore, the access to mental health services need to be made more accessible by the women at all levels of mental health care service delivery [42]. Although Bangladesh has formally a well-structured three tier health care delivery system [56], due to dearth of mental health professionals and poor logistic support, this existing system is not functioning well for mental health conditions [57].

Management of psychotic depression requires treatment from psychiatrists who are mainly available in the tertiary care hospitals in major cities [40]. Primary care services lack adequately trained personnel to identify and treat depression as a single condition or in association with particular chronic disorders. Although training and services to address psychiatric conditions are gradually increasing, vast majority of mental health patients yet to get the benefit of such initiatives as they have limited access [45,57]. Most of the psychotropic medications are available in Bangladesh yet psychotherapy is hardly available. Bangladesh lacks a mental health act although a draft bill is in the final stage but is yet to be approved by the authorities.

\section{Conclusions}

This review showed that researches on mental disorders are not at satisfactory level in Bangladesh given the magnitude of the problem. To improvise the mental health services in Bangladesh, further well-designed epidemiological and clinical research are needed. Public education and awareness campaigns on mental health conditions may be undertaken to ameliorate misconceptions.

\section{Competing interests}

The authors declare that they have no competing interests.

\section{Authors' contributions}

$\mathrm{MH}$ participated in the conception, design, coordination, acquisition of literature, analysis and interpretation of data, and drafting/revising the manuscript. HA participated in the acquisition of data and manuscript drafting and revisions. WC and LN participated in the conception, design and drafting. DA conceived the study, guided drafting, and substantially contributed to the design, acquisition of literature, analysis and interpretation of data, and revised the draft critically for important intellectual contents. All authors read and approved the final manuscript.

\section{Acknowledgements}

We gratefully acknowledge the contribution of Muhammad Ashique $\mathrm{H}$. Chowdhury, Ali Tanweer Siddiquee, Shyfuddin Ahmed, Sonia Pervin, Sholeh Rahman and Mohammad Tauhidul Islam on behalf of the Centre for Control of Chronic Diseases (CCCD), International Centre for Diarrheal Disease Research, Bangladesh (icddr,b) for their comments and valuable suggestions on the initial draft. We thank Avra Das Bhowmik and Faruk Alam from National Institute of Mental Health (NIMH), Dhaka, Bangladesh for their insightful comments. This work did not require any additional funding. DA and $\mathrm{MH}$ are supported by icddr,b which acknowledges with gratitude the commitment of the Centre's donors for their generous support to its research efforts. 


\section{Author details}

${ }^{1}$ Centre for Control of Chronic Diseases (CCCD), International Centre for Diarrheal Disease Research, Bangladesh (icddr,b), 68 Shaheed Tajuddin Ahmed Sharani, Mohakhali, Dhaka 1212, Bangladesh. ${ }^{2}$ National Institute of Mental Health (NIMH), Sher-E-Bangla Nagar, Dhaka 1207, Bangladesh. ${ }^{3}$ Liverpool School of Tropical Medicine, Pembroke PI, Liverpool, Merseyside L3 5QA, UK. ${ }^{4} J o h n s$ Hopkins Bloomberg School of Public Health, Baltimore, MD, USA.

Received: 18 November 2013 Accepted: 18 July 2014

Published: 30 July 2014

\section{References}

1. Mathers C, Fat DM, Boerma JT: The global burden of disease: 2004 update. Geneva: WHO press; 2008.

2. Bass JK, Bornemann TH, Burkey M, Chehil S, Chen L, Copeland JRM, Eaton WW, Ganju V, Hayward E, Hock RS, Kidwai R, Kolappa K, Lee PT, Minas H, Or F, Raviola GJ, Saraceno B, Patel V: A United Nations General Assembly Special Session for Mental, Neurological, and Substance Use Disorders: The Time Has Come. PLoS Med 2012, 9(1):e1001159. doi:10.1371/journal. pmed.1001159.

3. Hock RS, Or F, Kolappa K, Burkey MD, Surkan PJ, Eaton WW: A new resolution for global mental health. Lancet 2012, 379(9824):1367-1368. doi:10.1016/S0140-6736(12)60243-8.

4. Colton CW, Manderscheid RW: Congruencies in Increased Mortality Rates, Years of Potential Life Lost, and Causes of Death Among Public Mental Health Clients in Eight States. Prev Chronic Dis 2006, 3(2):A42 [http://www. ncbi.nlm.nih.gov/pmc/articles/PMC1563985/pdf/PCD32A42.pdf]

5. Moher D, Liberati A, Tetzlaff J, Altman DG, The PRISMA Group: Preferred Reporting Items for Systematic Reviews and Meta-Analyses: The PRISMA Statement. PLoS Med 2009, 6(7):e1000097. doi:10.1371/journal.pmed.1000097.

6. Selim N, Satalkar P: Perceptions of mental illness in a Bangladesh village. BRAC University Journal 2008, 5(1):47-57.

7. Wilce JM: The poetics of "madness": Shifting codes and styles in the linguistic construction of identity in Matlab, Bangladesh. Cult Anthropol 2000, 15(1):3-34. doi:10.1525/can.2000.15.1.3

8. Wilce JM: Coping with the Language of Madness in Rural Bangladesh: Aesthetics and Language Ideologies. 1998, 1:13-26 [http://www.sscnet. ucla.edu/CLIC-GSA/journal/1998/wilce1998.pdf]

9. Selim N: Cultural dimensions of depression in Bangladesh: A qualitative study in two villages of Matlab. J Health Popul Nutr 2010, 28(1):95-106 [http:// www.ncbi.nlm.nih.gov/pmc/articles/PMC2975851/pdf/jhpn0028-0095.pdf]

10. Noykhovich EY, Bulage PR, Hossain MD: Perceptions of Mental Illness among adolescents in Bagnibari Village. BRAC University Journal 2012, (Special Issue):11-20 [http://sph.bracu.ac.bd/images/Journal/ brac_university_journal_2012.pdf]

11. Rabbani MG, Alam MF, Ahmed HU, Sarkar M, Islam MS, Anwar N, Zaman MM, Chowdhury S, Chowdhury MWA, Das SK, Hamid MA, Islam MT, Mohit MA, Jahan NA, Rahman AHM, Chowdhury S, Chowdhury KP, Wahab MA, Rahman F, Mandal MC, Hossain MD, Bhowmik AD, Bashar MK, Khan NM, Uddin MJ, Khan MZR: Prevalence of mental disorders, mental retardation, epilepsy and substance abuse in children. Bang J Psychiatry 2009, 23(1):1-54

12. National Institute of Mental Health \& Hospital (Bangladesh), WHO Bangladesh: Prevalence, Medical Care, Awareness and Attitude Towards Mental Illness in Bangladesh. In Edited by Karim ME, Zaman MM. 2007:1-27 [http://books. google.com.bd/books/about/Prevalence_Medical_Care_Awareness_and_At. html?id=cixINwAACAAJ\&redir_esc=y]

13. Chowdhury AK, Salim M, Sakeb N: Some aspects of psychiatric morbidity in the out-patient population of a general hospital. Bangladesh Med Res Counc Bull 1975, 1(1):51-59 [http://www.bmrc.org.bd/webAdmin/finalarticle/ AKM\%20Nazimuddowla\%20Chowdhury\%20(51-59).pdf]

14. Alam MN: Psychiatric morbidity in general practice. Bangladesh Med Res Counc Bull 1978, 4(1):38-42 [http://bmrc.org.bd/webAdmin/finalarticle/MN\% 20lslam\%20(Page\%2038\%20-42).pdf]

15. Chowdhury AK, Alam MN, Ali SMK: Dasherkandi project studies. Demography, morbidity and mortality in a rural community of Bangladesh. Bangladesh Med Res Counc Bull 1981, 7(1):22-39.

16. Islam MM, Ali M, Ferroni P, Underwood P, Alam MF: Prevalence of psychiatric disorders in an urban community in Bangladesh. Gen Hosp Psychiatry 2003, 25(5):353-357. doi:10.1016/S0163-8343(03)00067-7.
17. Karim E, Alam MF, Rahman AHM, Hussain AAM, Uddin MJ, Firoz AHM: Prevalence of Mental IIIness in the Community. TAJ 2006, 19(1):18-23 [http://www.banglajol.info/index.php/TAJ/article/download/3163/2662]

18. Monawar Hosain GM, Chatterjee N, Ara N, Islam T: Prevalence, pattern and determinants of mental disorders in rural Bangladesh. Public Health 2007, 121(1):18-24. doi:10.1016/j.puhe.2006.06.018.

19. Ara N, Hossain GMM, Islam MT: Women mental health in rural part of Bangladesh. Bang J Psychiatry 2001, 15(2):5-10.

20. Rabbani MG, Hossain M: Behaviour disorders in urban primary school children in Dhaka, Bangladesh. Public health 1999, 113(5):233-236 [http://ac.els-cdn.com/S0033350699001651/1-s2.0-S0033350699001651-main. pdf?_tid=950c98c8-d4f2-11e3-9375-00000aacb360\&acdnat=1399362595_ 11 b952cd3f1399d713240dd84746e5c8]

21. Jahan NA, Hasan MK, Mohit MA: Prevalence Of Psychiatric Disorders Among Socially Disadvantaged Children. Bang J Psychiatry 2004, 18(2):27-40.

22. Mullick MSI, Goodman R: Questionnaire screening for mental health problems in Bangladeshi children: a preliminary study. Soc Psychiatry Psychiatr Epidemiol 2001, 36(2):94-99. doi:10.1007/s001270050295.

23. Mullick MSI, Goodman R: The prevalence of psychiatric disorders among 5-10 year olds in rural, urban and slum areas in Bangladesh: an exploratory study. Soc Psychiatry Psychiatr Epidemiol 2005, 40(8):663-671. doi:10.1007/s00127-005-0939-5.

24. Khan NZ, Ferdous S, Islam R, Sultana A, Durkin M, McConachie H: Behaviour problems in young children in rural Bangladesh. J Trop Pediatr 2008, 55(3):177-182. doi:10.1093/tropej/fmn108.

25. Moussavi S, Chatterji S, Verdes E, Tandon A, Patel V, Ustun B: Depression, chronic diseases, and decrements in health: results from the World Health Surveys. Lancet 2007, 370(9590):851-858. doi:10.1016/S0140-6736(07)61415-9.

26. Asghar S, Hussain A, Ali SMK, Khan AKA, Magnusson A: Prevalence of depression and diabetes: A population based study from rural Bangladesh. Diabet Med 2007, 24(8):872-877. doi:10.1111/j.1464-5491.2007.02136.x.

27. Karim ME, Firoz AHM, Alam MF: Assessment of Depression in Parkinson's disease, Psoriasis, Stroke, and Cancer patients. Bang J Psychiatry 2001, 15(2):11-18.

28. Chowdhury NN, Jahan NA, Sobhan MA, Islam H, Islam T, Salam MA, Morshed NM, Chowdhuri NS, Mullick MSI: Psychiatric Morbidity in Hospitalized Cancer Patients. Bang J Psychiatry 2007, 21(1):50-56.

29. Ali M, Firoz AHM, Qusar MMAS, Ahsan SM, Mohsin AS: Psychiatric disorders among patients attending outpatient departments of different disciplines. Bang J Psychiatry 2007, 21(1):39-49.

30. Roy T, Lloyd CE, Parvin M, Mohiuddin KGB, Rahman M: Prevalence of co-morbid depression in out-patients with type 2 diabetes mellitus in Bangladesh. BMC Psychiatry 2012, 12(1):123. doi:10.1186/1471-244X-12-123.

31. Hussain A, Rahim MA, Azad Khan AK, Ali SMK, Vaaler S: Type 2 diabetes in rural and urban population: diverse prevalence and associated risk factors in Bangladesh. Diabet Med 2005, 22(7):931-936. doi:10.1111/j.1464-5491.2005.01558x

32. Bhowmik B, Munir SB, Hossain IA, Siddiquee T, Diep LM, Mahmood S, Mahtab H, Khan AK, Hussain A: Prevalence of type 2 diabetes and impaired glucose regulation with associated cardiometabolic risk factors and depression in an urbanizing rural community in bangladesh: a population-based cross-sectional study. Diabetes Metab J 2012, 36(6):422-432. doi:10.4093/dmj.2012.36.6.422.

33. Rahman M, Rahman MA, Flora MS, Rakibuz-Zaman M: Depression and associated factors in diabetic patients attending an urban hospital of Bangladesh. IJCRIMPH 2011, 3(1):65-76 [http://iomcworld.com/ijcrimph/ ijcrimph-v03-n01-07.htm]

34. Giasuddin NA, Chowdhury NF, Hashimoto N, Fujisawa D, Waheed S: Pathways to psychiatric care in Bangladesh. Soc Psychiatry Psychiatr Epidemiol 2012, 47(1):129-136. doi:10.1007/s00127-010-0315-y.

35. Islam H, Noman SZ, Shaheed AYM, Chowdhury NN: Referral Pattern of Patients to a Psychiatric Outpatient Clinic of Dhaka City. Bang J Psychiatry 2008, 22(1):22-28

36. Islam MT, Uddin MMJ, Ahmed HU, Rabbani MG: Treatment Practices by Traditional Healers in Treatment of Psychiatric Patients - A community centre study. Bang J Psychiatry 2009, 23(2):30-35.

37. Fahmida A, Wahab MA, Rahman MM: Pattern of psychiatric morbidity among the patients admitted in a private psychiatric clinic. BJMS 2009, 8(1-2):23-28 [http://www.banglajolinfo/index.php/BJMS/article/viewFile/3186/2681]

38. Rahman AHMM, Khan MZR, Sarkar M, Firoz AHM, Karim ME, Alam MF, Hamid MA: Study of Morbidity and Referral System Psychiatric Private Practice. Bang J Psychiatry 2006, 20(2):43-49. 
39. Chowdhury SH, Muztaba S, Hasan A: Referral pattern of psychiatric patients to pabna mental hospital. Ban J Psychiatry 1995, 7(1):9-12.

40. Ahmed HU, Mullick MSI, Alam MF, Nahar JS, Chowdhury NF, Hamid MA, Rabbani MG: Management of Psychotic Depression in Bangladesh. JSPN 2011, SS46-SS50 [https://www.jspn.or.jp/journal/symposium/pdf/jspn106/ ss046-050_bgsdng11.pdf]

41. Mohit MA, Maruf MM, Ahmed H, Alam MT: Depression and Physical Illnesses: an Update. BMJ 2011, 40(1):53-58 [http://www.banglajol.info/ index.php/BMJ/article/viewFile/9966/7403]

42. Jahan NA: Women's Mental Health- their problems, their disorders. Bang J Psychiatry 2001, 15(2):79-83.

43. Islam R, Howard R: Foreign report: Psychiatry in Bangladesh. Psychiatric Bulletin 1993, 17(8):492-494 [http://pb.rcpsych.org/content/17/8/492.full.pdf]

44. Rahman MZ, Sarkar M, Rabhani GM, Alam F, Wahab A, Firoz AHM: Child and Adolescent Mental Health Services in Bangladesh. Bang J Psychiatry 2008, 22(1):59-66.

45. Karim MRF, Shaheed F, Paul S: Psychiatry in Bangladesh. In Bulletin of the Board of International Affairs of the Royal College of Psychiatrists. Edited by Henderson J, Jackson R, Jenkins R, Loza N, Martindale B, Saxena S, Skuse D. Int Psychiatry 2006, 3(3): 16-18. [http://www.rcpsych.ac.uk/pdf/ip_jul06.pdf]

46. Math SB, Srinivasaraju R: Indian Psychiatric epidemiological studies: learning from the past. Indian J Psychiatry 2010, 52(Suppl 1):S95-S103. doi:10.4103/0019-5545.69220.

47. Mirza I, Jenkins R: Risk factors, prevalence, and treatment of anxiety and depressive disorders in Pakistan: systematic review. BMJ 2004, 328(7443):794. doi:10.1136/bmj.328.7443.794.

48. Centers for Disease Control and Prevention: Mental Health and Chronic Diseases. In National Center for Chronic Disease Prevention and Health Promotion- Division of Population Health, Volume Issue Brief No. 2012:1-6 [http://www.cdc.gov/nationalhealthyworksite/docs/ssue-Brief-No-2-MentalHealth-and-Chronic-Disease.pdf]

49. Prince M, Patel V, Saxena S, Maj M, Maselko J, Phillips MR, Rahman A: No health without mental health. Lancet 2007, 370(9590):859-877. doi:10.1016/S0140-6736(07)61238-0.

50. Anderson RJ, Freedland KE, Clouse RE, Lustman PJ: The prevalence of comorbid depression in adults with diabetes. Diabetes Care 2001, 24(6):1069-1078. doi:10.2337/diacare.24.6.1069.

51. Lustman PJ, Anderson RJ, Freedland KE, De Groot M, Carney RM, Clouse RE: Depression and poor glycemic control: a meta-analytic review of the literature. Diabetes Care 2000, 23(7):934-942. doi:10.2337/diacare.23.7.934.

52. Zahid N, Asghar S, Claussen B, Hussain A: Depression and diabetes in a rural community in Pakistan. Diabetes Res Clin Pract 2008, 79(1):124-127. doi:10.1016/j.diabres.2007.07.006.

53. Gadit AAM, Mugford G: Prevalence of depression among households in three capital cities of Pakistan: need to revise the mental health policy. PLoS One 2007, 2(2):e209. doi:10.1371/journal.pone.0000209.

54. Raval A, Dhanaraj E, Bhansali A, Grover S, Tiwari P: Prevalence \& determinants of depression in type 2 diabetes patients in a tertiary care centre. Indian J Med Res 2010, 132(2):195-200 [http://www.ijmr.org.in/temp/ IndianJMedRes1322195-2664831_072408.pdf]

55. Firoz AHM, Karim MDE, Alam MF, Rahman AHMM, Zaman MM, Rabbani MG: Awareness, Care and Acceptance of Mental Patients: A Nationwide Multicentric Community Survey in Bangladesh. Journal of NIMH 2009, 1(1):9-30,

56. Alam DS, Robinson H, Kanungo A, Hossain MD, Hassan M: Health Systems Preparedness for responding to the growing burden of noncommunicable disease-a case study of Bangladesh. In Health Policy \& Health Finance knowledge Hub. The Nossal Institute for Global Health. The University of Melbourne, Volume Working Paper Series Number 25. 2013:1-25 [http://ni.unimelb.edu.au/_data/assets/pdf_file/0008/720656/WP25.pdf]

57. World Health Organization, Ministry of Health \& Family Welfare Bangladesh: WHO-AIMS Report on Mental Health System in Bangladesh. In A report of the assessment of the mental health system in Bangladesh using the World Health Organization - Assessment Instrument for Mental Health Systems (WHO-AIMS). 2007:1-20 [http://www.who.int/mental_health/ bangladesh_who_aims_report.pdf]

\section{doi:10.1186/s12888-014-0216-9}

Cite this article as: Hossain et al:: Mental disorders in Bangladesh: a systematic review. BMC Psychiatry 2014 14:216.

\section{Submit your next manuscript to BioMed Central and take full advantage of:}

- Convenient online submission

- Thorough peer review

- No space constraints or color figure charges

- Immediate publication on acceptance

- Inclusion in PubMed, CAS, Scopus and Google Scholar

- Research which is freely available for redistribution 